\title{
Assessment and interpretation of corneal endothelial cell morphology and function following cryopreservation
}

\author{
P. W. MADDEN AND D. L. EASTY \\ From the Department of Surgery, University of Bristol
}

SUMMARY Scanning electron microscopy, specular microscopy, and staining techniques were used in a short-term study of the standard method of cryopreservation. Correlation of the techniques revealed that the endothelium had an atypical morphology, showed apparent evidence of latent cell damage, and lacked function.

\begin{abstract}
A successful and simple technique for corneal cryopreservation continues to hold out the hope for indefinite storage and easy transport over long distances. It would enable setting up a tissue bank which could be used for the close matching of donor and recipient by typing techniques ${ }^{12}$ and allow the use of tissue in regions where donor material is unavailable. Early investigations of preservation techniques ${ }^{3-6}$ have led to the development of the present clinical method. ${ }^{7}$ The studies employed vital staining, endothelial culture, and keratoplasty in animals to assess survival and function. Specular microscopy ${ }^{89}$ and scanning electron microscopy ${ }^{10}$ were not employed at this initial stage, but more recently there have been reports of the appearance of the endothelium in preserved tissue using transmission and scanning electron microscopy. ${ }^{11-13}$

The purpose of this report is to describe morphological changes in the endothelium of cryopreserved corneae using specular microscopy and scanning electron microscopy. Endothelial function is also to be assessed by the measurement of corneal thickness maintenance in a perfusion system.
\end{abstract}

\section{Materials and methods}

Dutch rabbits were killed with pentobarbitone. The eyes were immediately enucleated and precooled to $+4^{\circ} \mathrm{C}$ along with the preservation solutions of dimethyl sulphoxide and sucrose in albumin or serum.

Correspondence to Mr P. W. Madden. Department of Surgery, Bristol Royal Infirmary, Bristol BS2 8HW.
Freezing to $-196^{\circ} \mathrm{C}$ and thawing were carried out according to the method of Capella and Kaufman ${ }^{7}$ by the prescribed cooling box, ${ }^{14}$ or by a method designed to reduce mechanical trauma. In the second method corneae were mounted on specular microscopy rings and frozen endothelium-side-up in $5 \mathrm{ml}$ solution in plastic scintillation vials. Freezing and thawing profiles were suitably adjusted for the different thermal properties of the plastic vial. Any subsequent staining or fixation procedure was undertaken with the corneae still mounted.

Nitroblue tetrazolium was used to demonstrate viable cells after 3 hours incubation. After fixation for scanning electron microscopy (SEM) with glutaraldehyde and osmium tetraoxide ${ }^{10}$ the specimens were viewed at $9.5 \mathrm{kV}$ on a Cambridge $\mathrm{S} 4$ microscope. Post-thaw incubation prior to SEM was carried out at $35^{\circ} \mathrm{C}$ in glutathione bicarbonate ringer (GBR at $\mathrm{pH}$ $7 \cdot 4) .{ }^{15}$ This solution was also used for perfusion of mounted cornea on the specular microscope. Specular microscopy was used to assess corneal function by serial thickness measurements. The average of 3 readings from endothelium to the stromal/epithelium interface was taken. The microscope was also used to assess cell morphology.

\section{Results}

Immediately after the freeze/thaw cycle nitroblue tetrazolium staining demonstrated, at best, $70 \%$ endothelial survival as shown by dye precipitation resulting from retention of normal intracellular oxidative enzymes. 


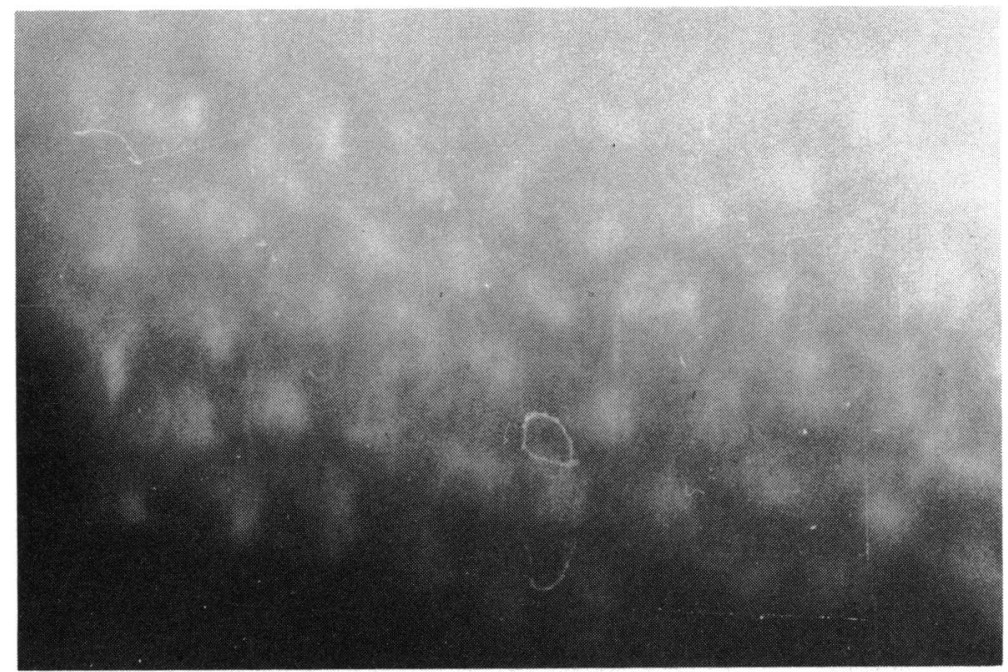

Fig. 1 Specular image immediately after the freeze/thaw cycle $(\times 570)$.

Specular microscopy in normal corneae showed an initially darkened cell layer, which with the passage of time lightened and lost granularity as the cell margins became more distinct. The normal polygonal appearance was retained for over 6 hours after which the cells darkened and the cornea became cloudy.

When corneae were treated with the preserving solutions without freezing only slight morphological change occurred. The cells darkened and became slightly granular. Occasional dark dots made transient appearances along the cell margins. Specular microscopy immediately after thawing frozen tissue showed the endothelium as a dark field with granular central bright areas approximately half the size of a normal cell (Fig. 1). Cloudiness of the stroma made it difficult to view late cellular changes. The majority of the bright areas enlarged within the first 10 minutes of perfusion and small bright bodies occurred, apparently, in the cell cytoplasm. Examination of the central cornea revealed an occasional dark zone the size of a single cell. Clarity was gradually reduced and few preparations allowed examination after 2 hours.

Morphological examination of untreated control corneae with the SEM presented a regular array of polygonal endothelial cells with sharply defined, interdigitating cell borders. The surface was relatively smooth except for small particles. This image was still evident after 6 hours of perfusion (Fig. 2a). Immediately after the freeze/thaw cycle SEM revealed a generalised cell surface pitting (Fig. 2b). In contrast to the controls there were no obvious cell junctions. The cellular nature could be distinguished by the apparently prominent nuclei. Tissue fixed 3 hours after perfusion revealed gross changes in a small proportion of cells. Isolated cells had ruptured and detached from the cell layer. After 6 hours perfusion there was general disruption of the cell layer (Fig. $2 c)$. The cells had rounded and drawn back from each other, remaining joined only by thin bridges. There was surface pitting with many surface fenestrations.

Serial measurements of corneal thickness were plotted graphically to give a dynamic representation of endothelial function. When controlled corneae were removed from $+4^{\circ} \mathrm{C}$ on this system, after a lag period thinning occurred at a rate of $20 \mathrm{~mm} \times 10^{-3} \mathrm{~h}^{-1}$. A normal thickness of 380 to $400 \mathrm{~mm} \times 10^{-3}$ was achieved and maintained. Thickness maintenance continued for at least 6 hours after mounting. Nonfrozen cryoprotective treated corneae gave atypical maintenance thickness curves (Fig. 3). Thickness maintenance eventually occurred but usually at a higher than normal thickness. Freeze/thaw corneae were initially thin $\left(325 \mathrm{~mm} \times 10^{-3}\right)$ owing to the hyperosmotic nature of the preservatives. Thickness increased at a rate of at least $200 \mathrm{~mm} \times 10^{-3} \mathrm{~h}^{-1}$ until clarity was lost (Fig. 4). Both frozen and nonfrozen (in GBR) 'stromal' preparations, where the epithelium and endothelium had been removed, increased in thickness at a rate of $800 \mathrm{~mm} \times 10^{-3} \mathrm{~h}^{-1}$ on perfusion (Fig. 4).

\section{Discussion}

We deduce from this study that during incubation after the freeze/thaw cycle there was a gross disturbance of the endothelial monolayer. The morphological changes were observed with both the specular and scanning electron microscopes. Functional assessment of corneae with the specular microscope by thickness measurement showed that theri was a 


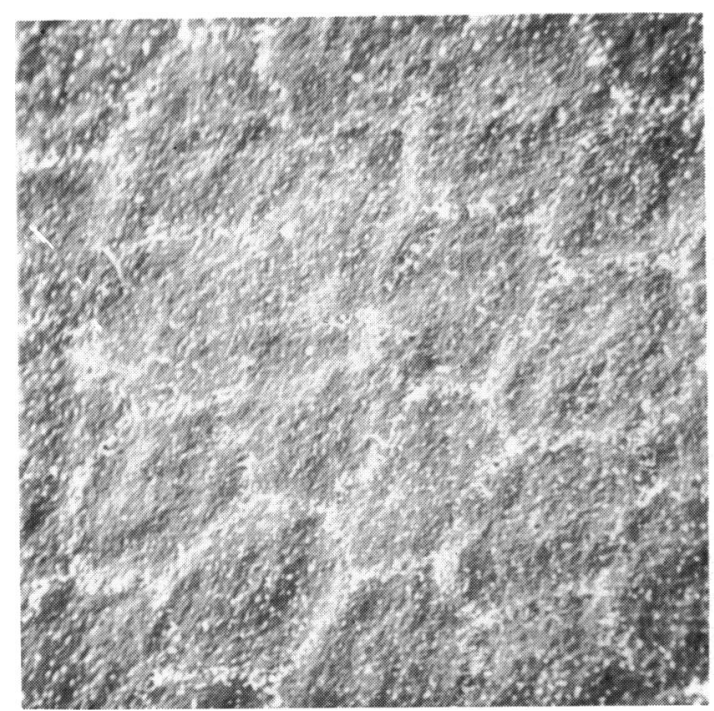

Fig. 2a

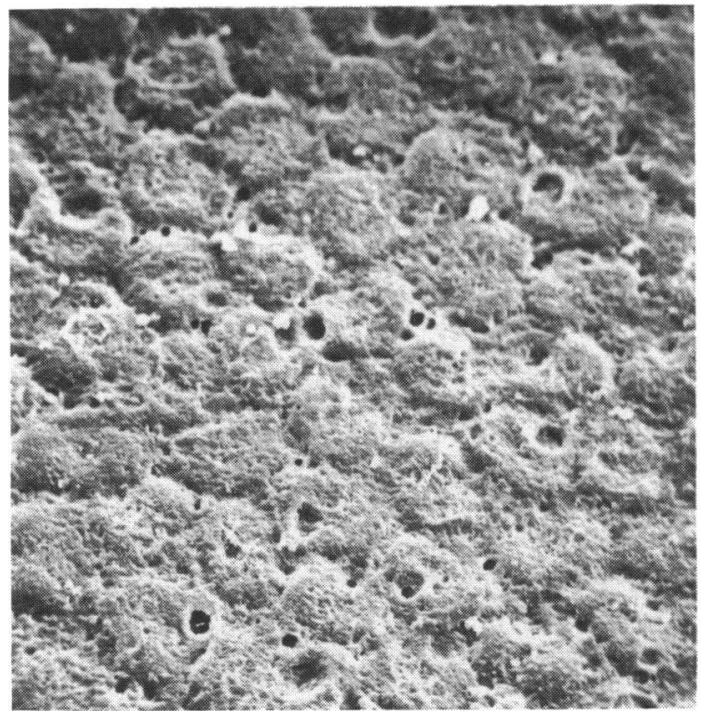

Fig. 2c

lack of water barrier function after freezing. This functional change was not a consequence of alterations in the swelling pressure of the corneal stroma, as similar thickening rates were achieved with both frozen and nonfrozen 'stromal' preparations. Toxicity studies at $+4^{\circ} \mathrm{C}$ of the cryoprotective solutions showed that only minimal changes in both morphology and function occurred before freezing. The gross changes seen after thawing must therefore have been as a result of the freeze/thaw cycle.

In previous in-vitro studies histochemical staining

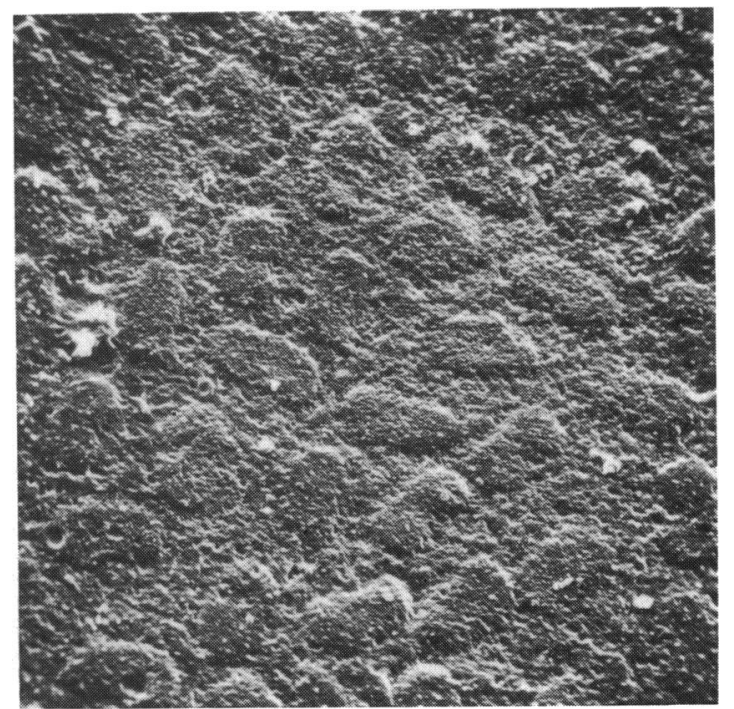

Fig. $2 b$

Fig. 2 Scanning electron microscopy of the corneal endothelium. (a) Normal after 6 hours' perfusion in gluthathione bicarbonate Ringer $(\times 1150)$. All boundaries are well defined and the cell surface smooth. (b) Immediately after the freeze/thaw cycle $(\times 1050)$. Apparent prominent nuclei. Indistinct cell boundaries and a general surface pitting. (c) Six hours of perfusion after the freeze/thaw cycle $(\times 770)$. Rounded swollen cells with extensive surface pitting and fenestration.

was the primary technique of viability assessment. This method is an index of cell wall permeability to intracellular enzymes. Thus a cell that cannot retain enzymes is considered nonviable. The technique is a useful stage in the assessment of endothelial survival. However, although the staining technique indicated cell viability and whether there was complete cell cover, it gave little indication as to whether this was an integrated cell layer with water barrier and pump function. Specular microscopy and scanning electron microscopy gave more detailed information on the 


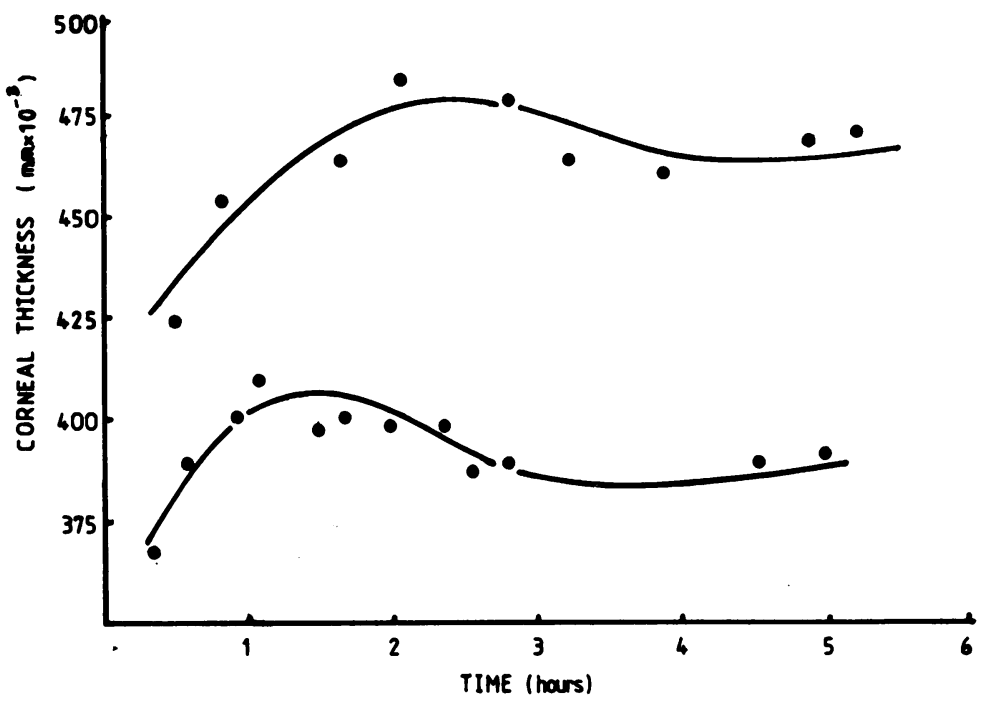

Fig. 3 Functional assessment of nonfrozen cornea pretreated with cryoprotective solutions, with the specular microscope to measure corneal thickness.

appearance of cell junctions and the cell layer. Both techniques showed that the cells were apparently all present immediately after the freeze/thaw cycle but had an atypical appearance. We consider that the bright areas seen with the specular microscope are cell nuclei. This image corresponds with the apparently elevated nuclei viewed by scanning electron microscopy. The techniques also gave evidence of individual cell breakdown during incubation, the dark areas shown by specular microscopy apparently correlating with individual cell rupture seen with the SEM. This disruption increases up to 6 hours, when SEM shows general disorganisation of the endothelial cell layer.
The lack of endothelial function after thawing was shown by the rapid increase in thickness. Such lack of water barrier function must be due to a combination of permeability changes in the endothelial cell wall. cell disruption, or loss of cell junction integrity, as pump inhibition alone would constitute a thickness increase of only $20 \mathrm{~mm} \times 10^{-3} \mathrm{~h}^{-1}$. We and others ${ }^{12}$ have shown that cell disruption and loss of integrity of cell junctions occur within hours. These changes could have been the manifestation of damage produced by freezing per se or have been caused by one of the many factors involved in post-thaw rehydration and the restarting of cell metabolism. The importance of the post-thaw period is further highlighted with in-

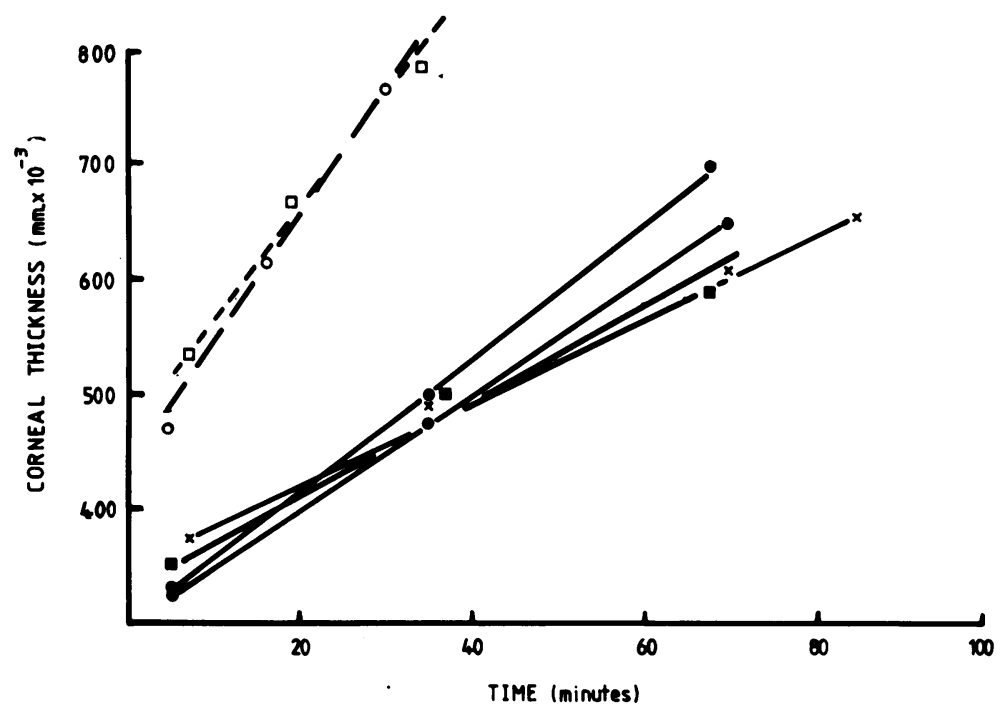

Fig. 4 Functional assessment after the freeze/thaw cycle (solid lines). Thickness assessment of stromal preparations (interrupted lines): $\square=$ frozen, $\bigcirc=$ non-frozen. 
vitro evidence of endothelial reversible damage. ${ }^{11}$

The aim of corneal cryopreservation is ultimate endothelial survival, not necessarily immediate normal function. Our results and other in-vitro studies ${ }^{11} 16$ should be taken in the context of the clinical successes ${ }^{17} 18$ that have been reported with cryopreserved corneae. It appears that there is a reorganisation of the endothelial layer after grafting. Postoperative corneae are opaque and nonfunctional, but clarity does return after several days.

There is therefore an indication for longer term studies, perhaps by employing organ culture as well as in-vivo techniques. Unfortunately the rabbit model is not suitable for long-term studies, as the endothelium is capable of rapid mitotic division. ${ }^{19}$ The human situation of an adult nonreplicating endothelium must be studied directly, or with a different animal model system.

We therefore conclude that modern techniques of in-vitro assessment show that the endothelium has an atypical appearance and is nonfunctional immediately after corneal cryopreservation. However, in spite of this the good clinical results achieved in the past prove that there must be long-term endothelial survival. Nonetheless it should now be possible, with new methods of assessment, to improve systems of corneal cryopreservation. The further development of such techniques is currently in progress with this aim.

We are grateful to the Wellcome Trust Foundation and the South West Regional Health Authority for funding the project. We thank Professor Peacock and Dr M. O. Symes, of the Department of Surgery, Bristol Royal Infirmary, for their support. The use of the scanning electron microscopes of the departments of Physics and Zoology, Bristol University, is gratefully acknowledged.

\section{References}

1 Vannas S, Tiilikainen A, Vannas A, Karjalainen K. HLA B12 and HLA B27 Antigens and susceptibility to the corneal allograft reaction. Acta Ophthalmol (Kbh) 1978; 56: 689-96.
2 Mailath L, Alberth B. Immunological investigations on patients with transplanted cornea. Albrecht von Graefes Arch Klin Ophthalmol 1975; 196: 181-5.

3 O'Neill P, Mueller FO, Trevor Roper PD. On the preservation of corneae at $-196^{\circ} \mathrm{C}$ for full thickness homografts in man and dog. Br J Ophthalmol 1967; 51: 13-29.

4 Mueller FO, O'Neill P, Trevor Roper PD. Full thickness corneal grafts in Addis Ababa, Ethiopia. Br J Ophthalmol 1967; 51: $227-45$.

5 Mueller FO, Smith AO. Some experiments on grafting frozen corneal tissue in rabbits. Exp Eye Res 1963; 2: 237-46.

6 Capella JA, Kaufman HE, Robbins JE. Preservation of viable corneal tissue. Arch Ophthalmol 1965; 74: 669-73.

7 Capella JA, Kaufman HE, Robbins JE. Preservation of viable corneal tissue. Cryobiology 1965; 2: 116-21.

8 Maurice DM. The location of the fluid pump in the cornea. $J$ Physiol 1972; 221: 43-54.

9 Dikstein S, Maurice DM. Metabolic bases to the fluid pump in the cornea. J Physiol 1972; 221: 29-41.

10 Cleveland PH, Schneider CW. A simple method of preserving ocular tissue for scanning electron microscopy. Vision Res 1968; 9:-1401-2.

11 Van Horn DL, Edelhauser HF, Gallun AB, Schultz RO. Reversability of ultra structural freeze thaw induced injury. Arch Ophthalmol 1972; 87: 422-6.

12 Van Horn DL, Hanna C, Schultz RD. Corneal cryopreservation; ultrastructural and viability changes. Arch Ophthalmol 1970; 84: 655-67.

13 Van Horn DL, Schultz RO. Endothelial survival in cryopreserved human corneae; a scanning electron microscopic study. Invest Ophthalmol Visual Sci 1974; 13: 7-16.

14 Capella JA. Technique of corneal cryopreservation. Washington, DC: Lion of District 22C Eye Bank, 1973.

15 Mayes KR. Hodson SA. An in vivo demonstration of the bicarbonate ion pump of rabbit corneal endothelium. Exp Eye Res 1979; 28: 699-707.

16 Walker WK, Lubczy KJ, Collani E. Die Vitatfarbung der Endothels kon servier ter Hornhaute mit Trypan blau. Klin Monatsbl Augenheilkd 1978; 173: 562-9.

17 Ruusuvaara P. Effects of corneal donor age, cadaver time and post-operative period on the graft endothelium. Acta Ophthalmol (Kbh) 1979; 57: 868-81.

18 Capella JA, Kaufman HE, Polack FM. Prognosis of keratoplasty in phakic and aphakic patients and the use of cryopreserved donor tissue. Trans Am Acad Ophthalmol Otolaryngol 1972; 76: 1275.

19 Van Horn DL, Sendele DD, Seideman S, Buco PJ. Regenerative capacity of the corneal endothelium in rabbit and cat. Invest Ophthalmol Visual Sci 1977; 16: 597. 